\title{
Glomerular Diseases as Extrahepatic Manifestations of Hepatitis C Virus Infection
}

\section{Hepatitis C Virus İnfeksiyonuna Bağlı Ekstrahepatik Manifestasyon Olarak Glomerüler Hastalıklar}

Dede SIT ${ }^{1}$, Bennur ESEN ${ }^{1}$, Mehmet Emin YILMAZ²

${ }^{1}$ Clinic of Internal Medicine, Bagcilar Training and Research Hospital, Istanbul, Turkey

${ }^{2}$ Clinic of Internal Medicine, Capa Private Hospital, Istanbul, Turkey

\section{ABSTRACT}

Hepatitis C virus (HCV) infection is a common and important health problem throughout the world not only leads to problems in liver, but also causes a variety of manifestations in almost all systems. HCV is a common virus found in chronic kidney disease. HCV can be the reason of both some pathologies which may lead to chronic kidney disease such as membranoproliferative glomerulonephritis (MPGN), and also crucial problems in patients with end-stage kidney diseases undergoing dialysis treatment. There is a positive correlation between cryoglobulinemia, secondary MPGN and HCV infection. Treatment of HCV related glomerular diseases may lead to many problems. Tolerability of drugs such as (standard and pegylated) interferon and ribavirin are reduced due to impaired renal function and require appropriate dose adaptation for the patient. In this article, hepatitis $\mathrm{C}$ virus induced glomerular pathologies and their treatments are discussed.

Key Words: HCV, glomerular diseases, membranoproliferative glomerulonephritis

\section{ÖZET}

Tüm dünyada yaygın görülen ve önemli bir sağlık sorunu olan hepatit $\mathrm{C}$ virüsü (HCV) infeksiyonu sadece karaciğer ile ilgili sorunlara yol açmakla kalmaz, aynı zamanda hemen tüm sistemlerde çeşitli manifestasyonlara neden olur. HCV kronik böbrek hastalığında sık görülen bir virüstür. HCV, membranoproliferatif glomerülonefrit (MPGN) gibi hem kronik böbrek hastalığı ile sonuçlanabilecek çeşitli patolojilerin ortaya çıkmasına yol açar, hem de diyaliz tedavisi gören son dönem böbrek yetmezliği hastalarında önemli yaşamsal sorunlara neden olabilir. HCV infeksiyonu sekonder MPGN ile krioglobulinemi arasında pozitif ilişki bulunmaktadır. HCV ile ilişkili glomerüler hastalıkların tedavisi çok sayıda sorunu beraberinde getirmektedir. Hastalarda böbrek fonksiyonları bozuk olduğu için tedavide kullanılacak (standart ve pegile) interferon ve ribavirin gibi ilaçların tolerabilitesi zorlaşmaktadır ve hastaya uygun doz adaptasyonu gerektirmektedir. Bu yazıda HCV'nin neden olduğu glomerüler patolojiler ve tedavileri tartışılmıştır.

Anahtar Sözcükler: HCV, glomerüler hastalıklar, membranoproliferatif glomerülonefrit

\section{Giriş}

İlk olarak 1989 yılında izole edilen Hepatiti C virüsü (HCV) esas olarak karaciğeri etkilemesine (1) rağmen oluşturduğu immünolojik mekanizmalarla tüm organizmada farklı klinik bulgu ve sendromlara neden olabilmektedir. Dünya Sağlık Örgütü ve Centers for Disease Control and Prevention (CDC) verilerine göre HCV infeksiyonu dünya nüfusunun \%3'ünü ve Amerikan toplumunun yaklaşık \%2'sini etkiler (2-6). Virüsün yaygınlığı coğrafi dağılımlar ve ülkesel faktörlerle etkilenmekte ve dünyada yaklaşık 150-200 milyon insanın HCV ile infekte olduğu tahmin edilmektedir (3). Yıllık 3-4 milyon yeni olgunun teşhis edildiği ve 350,000 kişinin de HCV'ye bağlı komplikasyonlardan kaybedildiği bildirilmektedir (7). Ülkemizde yapılan çeşitli çalışmalara göre HCV sıklığı \%1-2,4 arasında değişmektedir (8).

Hepatit C virüsü; parenteral yolla bulaşan, tüm dünyada yaygın görülen, hepatik morbidite ve mortalitenin önemli bir nedeni olan virüstür (4-8). CDC önerilerinin yaygın olarak uygulanması sonrası HCV ile yeni enfekte olan birey sayısı 
azalmakla birlikte, yüksek morbidite ve mortalite oranları nedeniyle hala önemli bir sağlık sorunu olmaya devam etmektedir (2).

Hepatit C virüsü; kronik karaciğer hastalıklarına yol açmasına karşın HCV ile enfekte hastaların yaklaşık \%40'ında en az bir ekstrahepatik immünolojik manifestasyon meydana gelir (3-5). Pascual 1990 yılında ilk HCV ile ekstrahepatik manifestasyonlar arasında ilişkiyi ortaya koymasından sonra HCV ile ilişkili çok sayıda sendrom tanımlanmıştır $(9,10)$. $\mathrm{Bu}$ sendromları tanımak önemlidir, çünkü $\mathrm{HCV}$ ile enfekte hastaların çoğunda hiçbir hepatik semptom yoktur. Sjögren sendromu, romatoid artrit ve sistemik lupus eritematozus gibi otoimmün hastalıklarla ilgi çekici birlikteliğinin yanı sıra, çok sayıda lenfoproliferatif ve inflamatuar sendromla da ilişkili olduğu bildirilmiştir $(4,10)$. Klinik, patolojik ve epidemiyolojik veriler HCV'e bağlı ekstrahepatik manifestasyonları 4 grupta incelenebileceğini göstermektedir (Tablo 1) (4).

Hepatit C infeksiyonu ile böbrek patolojileri arasında yakın ilişki bulunmaktadır. Kronik HCV infeksiyonu hem glomerüler hem de tubulointerstisyel hastalığa yol açarak potansiyel Kronik Böbrek Hastalığına $(\mathrm{KBH})$ yol açabilir $(7,11,12)$.

Hepatit C, son dönem böbrek yetmezliği (SDBY) hastalarında oldukça yaygın bir infeksiyon hastalığıdır ve prevalansı coğrafi dağılıma ve ülkelerin gelişmişlik derecelerine bağlı olarak değişmekle birlikte hemodiyaliz (HD) hastalarının $\% 8,5-75$ görülmektedir $(2,3)$. T.C. Sağlık Bakanlığı ve Türk Nefroloji Derneği 2012 kayıtlarında HD hastalarında \%6.77 (olguların \%0.57'si HBV ile kombine infekte) ve periton diyalizi (PD) hastalarında \%0 HCV seropozitifliği bildirmektedir (13). Ayrıca HCV seropozitifliği SDBY için artmış bir risk olduğu gösterilmiştir (14-16). Genel popülasyonla kıyaslandığında diyaliz hastalarında HCV infeksiyonunun yüksek prevalans ve insidansı, infeksiyonun nazokomiyal geçişini desteklemektedir.

Tablo 1. HCV bağlı ekstrahepatik manifestasyonlar (4)

- HCV ile güçlü birliktelik gösteren manifestasyonlar; miks kriyoglobulinemi...

- HCV ile anlamlı bir ilişki gösteren ancak patojenik mekanizmaları hala açık olmayan bozukluklar; B hücreli nonHodgkin lenfoma, diabetes mellitus, porfiria kutanea tarda, liken ruben planus...

- HCV infeksiyonu olan olgularda yüksek prevalans gösteren durumlar; idiopathic pulmoner fibrozis, otoimmun tiroidit, sicca sendromu, non-kriyoglobulinemik nefropati ve glomerülonefrit, aortik ateroskleroz..

- HCV ile ilişkisi anekdot gözlemlere dayanan bozukluklar; büyüme hormonu eksikliği, kronik pruritis, kardiyomiyopati, psöriazis, periferik veya nöropatiler, kronik poliartrit, romatoid artrit, poliartritis nodoza, Behçet sendromu, polimiyozit/dermatomiyozit, otoimmun hemolitik anemi...
$\mathrm{Bu}$ derlemede HCV ile ilişkili glomerülonefritler (GN) irdelenmiştir.

\section{Hepatit C Virüsü ve Glomerülonefrit}

İnfeksiyonlara sekonder gelişen glomerülopatilerin sık nedenlerinden biri de hepatit virüsleridir. HCV, hem doğal böbrekte hem de transplante böbrekte glomerüler hastalıklara sıklıkla yol açmaktadır. Kriyoglobulinemi ile ilişkili veya ilişkisiz membranoproliferatif glomerülonefrit (MPGN) görülebilen en sık GN tipidir. Diğer GN tipleri seyrek görülür. Ayrıca HCV ile tip 2 diyabetes mellitus arasındaki ilişki nedeniyle HCV infeksiyonu diyabetik nefropati progresyonunda hızlanmaya neden olur. HCV için uygulanan interferon ve diğer antiviral tedaviler de çeşitli glomerüler patolojilere yol açabilirler $(3,16)$. Aşikar böbrek hastalığı olmayan bireylerde HCV infeksiyonu ile mikroalbuminüri arasındaki ilişkinin varlığı bilinenden daha sık renal disfonksiyona neden olabileceğini düşündürmektedir (17). HCV ile ilişkili glomerüler bozukluklar Tablo 2'de gösterilmiştir.

\section{Etiyopatogenez}

HCV infeksiyonuna bağlı hemen hemen tüm glomerülopati formları görülebilir. Ancak glomerüler patolojinin oluşma mekanizması tam olarak bilinmemektedir. Aşikâr böbrek hastalığ 1 olmayan hastalarda bile HCV infeksiyonu seyri sırasında albuminüri bulunabilir $(1,3)$. Bu nedenle $\mathrm{HCV}$ infeksiyonun renal disfonksiyon üzerindeki etkileri belirlenebilen olgulardan daha sık görülmektedir. En güçlü ilişki esansiyel kriyoglobulinemik MPGN Tip 2 ile gösterilmiştir. HCV ile mikst kriyoglobulinemi sıklıkla birliktelik gösterirler (18-20). HCV ile infekte hastalarda \%10-50 oranlarda mikst kriyoglobulinemi bildirilmesine karşın belirgin vaskülit ancak \%2-3 oranında görülür (1-3). Dolayısıyla HCV ilişkili MPGN anlayabilmek için kriyoglobulieminin kısaca gözden geçirilmesinde yarar vardır.

\section{Tablo 2. HCV ile ilişkili glomeruler hastalıklar}

\section{Yaygın formlar}

- Kriyoglobulinemi ile ilişkili GN

Seyrek formlar

- Kriyoglobulinemi (-) MPGN

- Postinfeksiyöz glomerülonefrit

- IgA Nefropatisi

- Membranöz GN

- Fokal ve Segmental Glomerüloskleroz

- Minimal değişiklik gösteren hastalık

- Trombotik mikroanjiopati

- Fibriller veya immunotaktoid glomerülopati 
Tablo 3. Kriyoglobulinemiler (Brouet Sınıflaması)

Tip I

izole IgM gibi monoklonal immunoglobulinden oluşur. Genellikle plazma hücre diskrazileri ve lenfoproliferatif hastalıklarla birliktedir. Olguların \%10-15'ini oluşturur
Tip II (miks tip)

Esas olarak mikst poliklonal IgG ve monoklonal IgM (IgG ve IgA de olabilir) kriyopresipite olmasıyla meydana gelir. Olguların $\% 50$ - 60'ını olşturur

RF pozitiftir.

Otoimmun hastalıklar, hepatitler, lenfoproliferatif hastalıklar ve visseral leishmaniasis'de görülür.

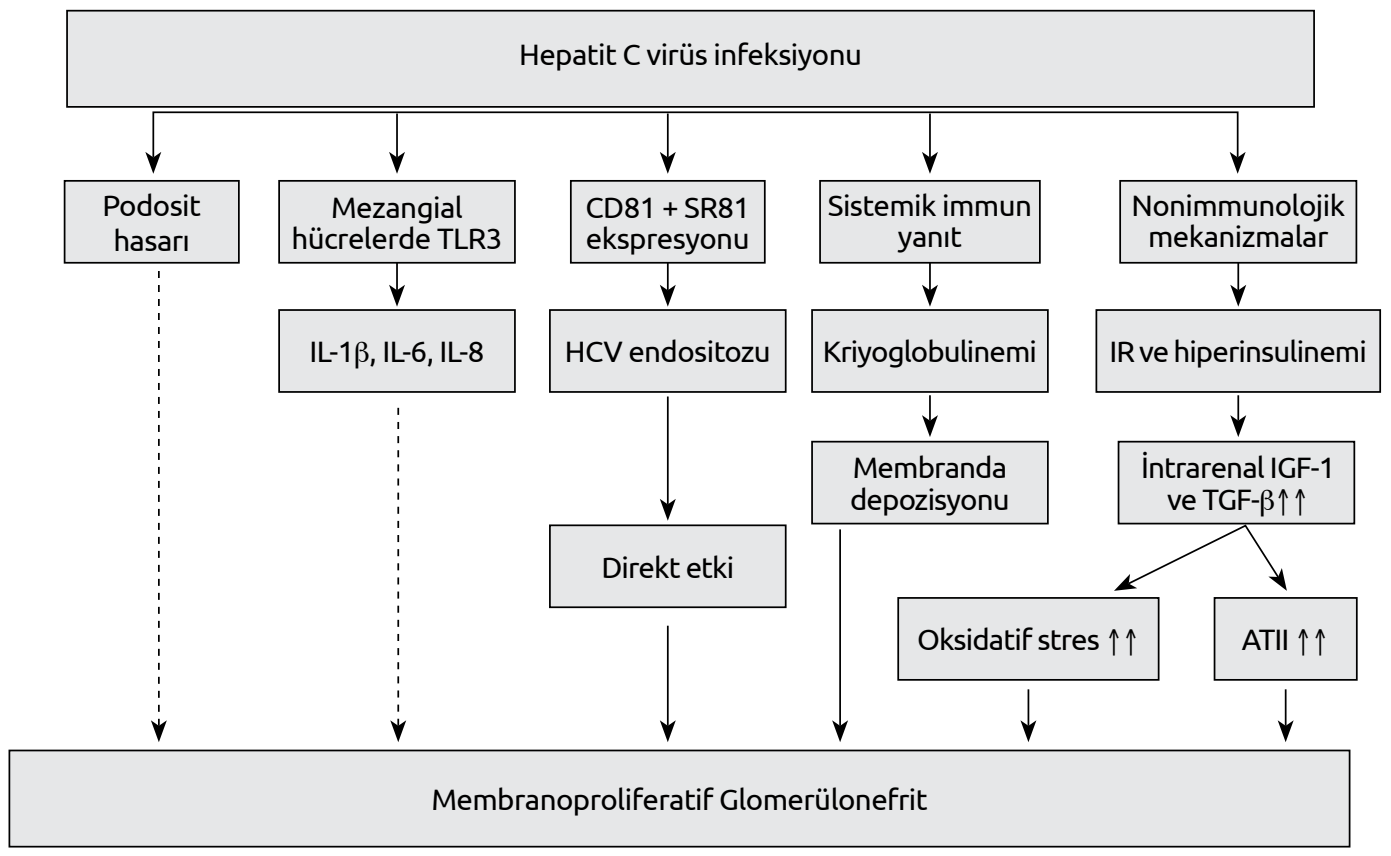

Şekil 1. Hepatit C virüs infeksiyonuna bağlı renal hasarın oluşma mekanizmaları (4)

\section{Mikst Kriyoglobulinemi (MK)}

İlk olarak Wintrobe ve Buell tarafindan multipl myelomalı hastada tanımlanan (21) kriyoglobulinler, düşük vücut ısısında $\left(<37^{\circ} \mathrm{C}\right)$ geri dönüşümlü olarak çöken monoklonal veya poliklonal immünoglobulinlerdir. Kriyoglobulinemi ise bu proteinlerin kanda saptanmasıdır $(22,23)$. MK, klinik bulguları küçük ve orta arterleri, kapillerleri ve venülleri etkileyen immün komplekslerle ilişkili sistemik vaskülite bağlıdır. Mikst kriyoglobulinemi klasik olarak Brouet klasifikasyon sistemine göre üç gruba ayrılır (24). Mikst kriyoglobulinemi infeksiyonlar, otoimmün hastalıklar ve lenfoproliferatif hastalıklar ile ilişkilidir (sekonder kriyoglobulinemi) (Tablo 3). MK'nin \%30-50'ni esansiyel kriyoglobulinemi meydana getirir ve bu formun \%90'ından fazlasindan HCV infeksiyonu sorumludur (18). HCV infeksiyonu ile ilişkili kriyogobulinemili bireyler genelde asemptomatik olmakla birlikte semptomatik olanlarda ise nonspesifik bulgular saptanır. Meltzer'in (25) tanımladığı palpabl purpura, asteni, artralji triadı bir ça- lışmada olguların ancak \%27,5'unda görülmüştür (26). Kriyoglobulineminin tanısı klinik ve laboratuar verilere dayanır. Romotoid faktör (RF) pozitif olan hastalarda kriyoglobulinemiden şüphelenilmelidir. Kronik HCV'li hastalarda asemptomatik kriyoglobulinemi olabilir (18). HCV ile tip II ve III MK arasında (27), bazı çalışmalarda tip I MK ile HCV 2a/c genotip arasında ilişki de bildirilmiştir (10). Kriyoglobulineminin glomerülonefrit, periferik nöropati ve jeneralize vaskülit gibi ciddi komplikasyonları oldukça yaygindır $(28,29)$. MPGN'de HCV prevalansı MK (+) olanlarda daha yüksek olmakla birlikte ülkeden ülkeye değişmektedir (29-31).

Hepatit C ile MK ilişkisi iyi bilinmesine karşın, HCV'nin MK'ye yol açma mekanizması açık değildir. Ancak virüsün periferik lenfositlere tropizm gösterdiği ve burada replikasyona uğradığı bilinmektedir $(28,29)$. LDL ve CD81 reseptörleri gibi birçok hücresel reseptör HCV'nin nonlenfoproliferasyonunda rol oynarlar. B lenfositlerinin yüzeyinde yer alan tetraspanin CD81 ligandını E2 zarf proteini 


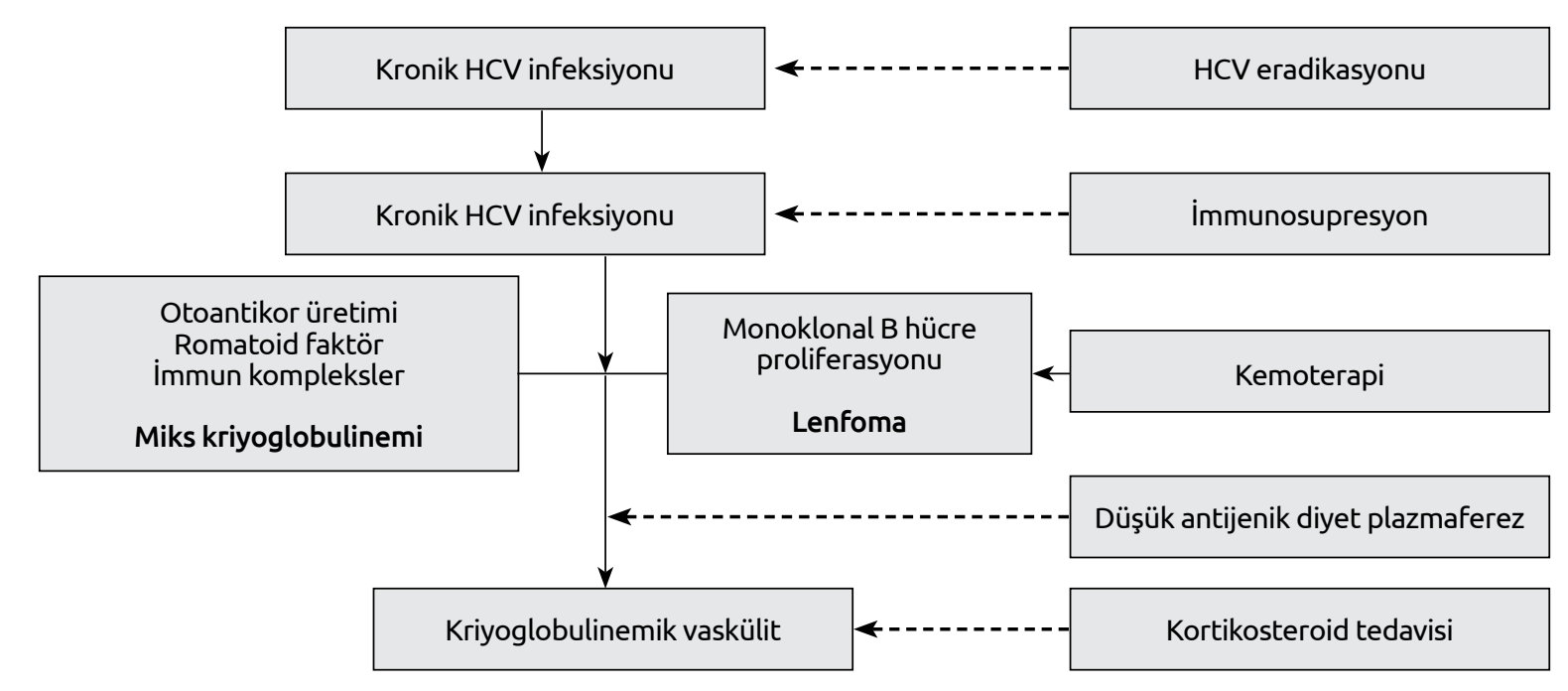

Şekil 2. HCV infeksiyonu ve tedavi (20)

vasıtasıyla bağlayan HCV, lenfositlerde proliferasyona neden olur. B hücrelerin klonal çoğalmaları ve CD81-E2 interaksiyonu antikor üretimi için gerekli olan antijen eşiğini düşürür ve kriyoglobulinleri meydana getirir. Kriyoglobulinler başlangıçta poliklonal IgG üretirler, devamında monoklonal immünoglobulinler ve monoklonal romatoid faktör meydana gelebilir (Tip II miks kriyoglobulinemi). İmmün sistemin kronik uyarılması immün komplekslerin üretimine neden olur (28). Çalışmalar HCV RNA konsantrasyonu ile MK arasında lineer bir ilişki olduğunu ortaya koymuştur (32). Ayrıca uzun dönem infeksiyon (33), HCV genotip 2a (34), siroz gibi ileri evre hastalık varlığı (35) ve HLA DRB1*11 (36) ilişkili olduğu, buna karşın HLA B27 pozitif olanlarda hiç MK görülmediği (37) iddia edilmiştir.

Hepatit C ile ilişkili MPGN oluşmasında immün kompleks mekanizma dışında diğer olası mekanizmalar immün komplekslerin hepatik klirenslerinin bozulmuş olması ve RF'nin direkt etki ile mezangium ve glomerülü tahrip etmesidir $(20,28)$.

Hepatit C infeksiyonu ile ilişkili renal manifestasyonların ekseriyeti MK ile birlikte ortaya çıkan MPGN'dir (38, 39). Daha az sıklıkta ise MK olmaksızın MPGN (40), fokal segmental glomerüloskleroz (41), membranöz glomerülopati (40), IgA nefropatisi (42), proliferatif glomerülonefrit (43), IgM nefropatisi (42), minimal değişiklik hastalığı (44), fibriler ve immünotaktoid GN (45), poliarteritis nodosa, vb. görülebilir. Ayrıca kresentik GN diğer glomerüler lezyonlara superpoze olabilir. HCV bağhı böbrek hasarının mekanizmaları Şekil 1'de özetlenmiştir (4).

\section{Klinik Belirti ve Bulgular}

Hastalarda gözlenen klinik bulgular genellikle MK'nın klinik bulgularına eklenmiş böbrek fonksiyon bozuklukları lodan sistemik vaskülite kadar değişmektedir. Glomerülopati; membranöz GN, fokal ve segmental glomerüloskleroz, postinfeksiyöz GN, trombotik mikroanjiopatiler, IgA nefropatisi ve fibriller veya immünotaktoid glomerülopati tarzında görülebilirse de hemen daima MPGN formundadır. Renal manifestasyonlar izole hematüri ve/veya proteinüriden aşikâr nefritik veya nefrotik sendrom ve akut böbrek yetmezliğine kadar değişebilmektedir. Çoğu vakada ciddi ve tedaviye yanıtsı hipertansiyon saptanabilir. Kronik HCV infeksiyonlu olgularda proteinüri geliştiğinde özellikle kriyoglobulinemi, RF pozitifliği ve hipokomplemantemi ile birlikte ise MPGN gözönünde bulundurulmalıdır. Kronik böbrek hastalığına progresyon sadece \%10 olguda gözlenebilir ve tedavisiz veya tedaviye yanıtsız olgularda sıktır (1-3).

Hepatit C pozitif hastalarda transplante böbrekte de novo glomerülopati gelişebileceği gibi rölaps glomerülopati şeklinde de görülebilir (46-48). Yüksek viral yük (47), ağır proteinüri (48) ve hipertansiyon (45) olanlarda relaps sıktır. Transplante böbrekte MPGN Tip I, fokal ve segmental glomerüloskleroz, minimal değişiklik hastalığı, membranöz GN ve trombotik mikroanjiopati gelişebilir (49).

Laboratuar: Kriyoglobulin testleri, serum total protein, albümin, immünoglobulin, kompleman, romatoid faktör, virolojik belirteçler (anti-HCV, HCV RNA ve genotipleri), kan biyokimyası, idrar analizleri yapılmalıdır. Cilt biyopsisinde tipik lökositoklastik vaskülit saptanabilir $(4,5)$. HCV ile ilgili MPGN tanısı serum anti-HCV antikorları ve HCV RNA pozitifliği ile konur. Plazma ve kriopresipitatta antiHCV, poliklonal IgG ve HCV RNA saptanır. HCV RNA konsantrasyonu, kriyopresipitatta seruma göre daha yüksektir (1000 kat fazla). ALT düzeyleri hastaların \%70'ınde artmıştır ve çoğunlukla serum kompleman (C1q, C4 ve C3) konsantrasyonları düşüktür (41); HCV RNA kriyoglobulinemi ile ilişkili MPGN'de yaklaşık \%81 saptanırken 
Tablo 4. HCV ile ilişkili kriyoglobulinemik glomerulonefritlerde tedavi (56)

Tip I

Orta düzeyde proteinüri ve/veya böbrek fonksiyonlarında hafif bozukluk (GFR $>50$ $\mathrm{mL} / \mathrm{dk} / 1,73 \mathrm{~m}^{2}$ )

Semptomatik tedavi

Antiviral tedavi (peg-IFN+RBV, 12 ay)

* Peg-IFN-a-2a $180 \mathrm{mg} / \mathrm{kg} / \mathrm{hf} \mathrm{sc}$ (veya GFR düşük hastalarda $135 \mathrm{mg} / \mathrm{hf}$ ); Peg-IFN-a-2b 1,5 mg/kg/hf sc (veya GFR düşük hastalarda $1,0 \mathrm{mg} / \mathrm{kg} / \mathrm{hf}$ )

* RBV $10-15 \mathrm{mg} / \mathrm{kg} / \mathrm{gün}$ - oral EPO (i.v./s.c.) (Hb düzeyine göre)
Tip II (miks tip)

Orta düzeyde proteinüri ve/veya böbrek fonksiyonlarında hafif bozukluk (GFR $>50$ $\mathrm{mL} / \mathrm{dk} / 1,73 \mathrm{~m}^{2}$ )

\section{Semptomatik tedavi}

Antiviral tedavi (peg-IFN-a + ribavirin, 12 ay)

Ribavirin genellikle önerilmez; ancak yakın izlemde:

* Düşük doz oral ribavirin (200 mg/gün veya $200-400 \mathrm{mg} \mathrm{3/hf)}$

* Haftalık Hb izlemi

* Yüksek doz EPO (20,000 veya 40,000 IU/hf iv/sc)
Tip III (miks tip)

Nefrotik düzeyde proteinüri ve/veya hızlı ilerleyen böbrek disfonksiyonu ve/veya kriyoglobulinemide alevlenme

Faz 1(vaskülit sendromu olan olgular):

* CCS: i.v. MP bolus (1-0,5 g/gün ardişık 3 gün) + oral CCS (0,5 mg/kg/gün yavaşça 0,1-0,2 mg/k/gün'e 4-6 ayda düşülür)

* Oral siklofosfamid (1-2 mg/kg/gün 2-4 ay)

* Plazmaferez (2-3 lt plazma ile 3/hf kez değişim, 2-3 hafta)

* Rituximab i.v. (375 mg/m2/hf 4 hafta)

Faz 2 (Vaskülit sendromları düzeldikten sonra): Antiviral tedavi

CCS: kortikosteroid; EPO: recombinant insan eritropoietini; Hb: hemoglobin; MP: metilprednizolon; RBV: Ribavirin, peg-IFN-a: pegile interferon-a

MK (-) olgularda \%25 oranında görülmektedir (1-4). Tip 2 kriyoglobulinemide HCV \%95'ten fazla olguda pozitif saptanır. Kesin tanı böbrek biyopsisi ile doğrulanır. Histolojik incelemelerde çoğunluğu makrofajların oluşturduğu glomerüler infiltrasyon izlenir. Glomerüler bazal membranda monositlerin bazal membran ile endotel arasında oluşturdu$\breve{g u}$ interpozisyona bağlı çift kontur görünümü izlenir. İmmunofloresan incelemelerde aktive RF ile birlikte IgG, IgM depozisyonu ve kompleman komponentlerinin birikimi saptanır. Elektron mikroskopide geniş subendotelyal depozidler izlenir. Vakaların \%25-30'unda küçük damar vaskülitleri izlenebilir (50-54).

\section{Tedavi}

Tedavinin başlanmasna karar verirken olası kar ve zarar dikkate alınmalıdır. Tedavi stratejisi temel olarak böbrek hastalı̆̆ının şiddetine bağlıdır. Tedavide amaç virüs eradikasyonudur (etiyolojik tedavi). Eradikasyonun mümkün olmadığı durumlarda ise MK üretiminin baskılanması hedeflenebilir. HCV ile ilişkili glomerülonefritlerin tedavisi 3 kategoride değerlendirilebilir: semptomatik, etiyolojik ve patogenetik tedavi. HCV ile ilişkili GN tedavi planı Şekil 2 ve Tablo 4'te özetlenmiştir $(31,55,56)$.

1. Semptomatik tedavi: HCV'ye yönelik hipoantijenik diyet (52), kolşisin gibi anti-inflamatuar ajan kullanımı ile ilgili veriler tartışmalıdır. Özellikle diğer tedavi modalitelerine yanit vermeyen hafif-orta MK olgularında önerilmektedir (53). Tüm hastalara renoprotektif önlemler (kan basıncının kontrolü, antiproteinürik ilaç kullanımı) uygulanmalıdır. Diüretikler, lipid düşürücü ajanlar ve renin-anjitensin-aldosteron sistemi üzerine etkili (anjiotensin dönüştürücü enzim inhibitörleri veya anjiotensin reseptör blokörleri) ve lipid düşürücü ilaçlar potansiyel olarak etkili ilaçlardır $(54,57)$.
2. Etiyolojik veya Antiviral Tedavi: Tedavi endikasyonları orta ve ağır renal tutulum bulguları (nefrotik sendrom, serum kreatinin düzeyinin yükselmesi, yeni başlayan hipertansiyon, böbrek biyopsisinde fibrozis veya tubulointerstisyel nefrit) veya progresif hastalıktır. MK ilişkili MPGN'nin en kesin tedavisi HCV'nin eradikasyonudur. Klinik ve histolojik olarak hafif-orta şiddette böbrek hasarı olan hastalar için ilk basamak tedavi antiviral tedavidir. HCV'ye karşı gelişen antikorlar, immün kompleksler ve viral replikasyonun eradikasyonu veya redüksiyonu amaçlanır. Güncel antiviral tedaviler; interferon $\alpha$ (IFN- $\alpha$ ), pegylated IFN $\alpha$ (peg-IFN- $\alpha$ ) ve ribavirinden (RBV) oluşmaktadır (58-62). Ayrıca telaprevir, boceprevir, ciluprevir, valopicitabin gibi antiviral ilaçlar ile toll-like reseptör agonistleri, nitazoxanide gibi immünomodülatörler deneme aşamasında olup gelecekte kullanılabilecek ilaçlardır (63).

Bir glikoprotein olan interferon (IFN) $\alpha$ veya peg-IFN- $\alpha$ (son zamanlarda rekombinant insan albümin ve interferon $\alpha-2 b$ kullanılmaya başlanan diğer bir formdur) ve bir nükleozid analogu olan RBV tek başlarına veya kombine kullanılabilirse de tek başına IFN- $\alpha$ tedavisine kıyasla peg-IFN + RBV kombinasyonu HCV eradikasyonunda daha etkin bulunmuştur (56, 64-66).

Ribavirin böbrek yetmezliği olanlarda kontrendikedir. RBV normal veya normale yakın böbrek fonksiyonu olan hastalarda tercih edilmelidir (67). Standart IFN- $\alpha$, antiviral etkinliği iyi olmasına karşın hemen tüm olgularda viremi, MK rekürensi ve yüksek doz gereksinimi nedeniyle kullanımı sınırlanmıştır (68). Bu nedenle Peg-IFN- $\alpha$ + RBV kombinasyonun tedavideki etkinliği günümüzde altın standart antiviral yaklaşım olarak kabul edilmektedir (69). Ancak relaps sıktır (70). Klinik yanıt genellikle geçici ve sınırlıdır. Kalıcı 
virolojik yanıt için tedavi süresi sınırlandırılmamalıdır; zira tedavi süresinin uzaması ile renal manifestasyonlarda düzelme elde edilebilir. Ayrıca IFN tedavisi glomerülonefrit, nöropati gibi vaskülitlerin aktive olmasına neden olurken, RBV de böbrekten atılımı nedeniyle ciddi renal disfonksiyonda kontrendikedir (67-72).

Antiviral tedavinin etkinliği tedavinin kesilmesinden sonraki 6. ayda HCV RNA düzeyinin ölçümü ile değerlendirilir. Yapılan çalışmalarda farklı genotiplerde kalıcı virolojik yanıt oranın değişebildiği görülmüştür. HCV genotip 2 veya 3 tipinde \%65-90 yanıt alınabilirken, genotip 1 de bu oran \%30-50 düzeylerinde bulunmuştur $(62,73)$. Feng ve ark. 11 klinik çalışmanın dahil edildiği 225 vakayı kapsayan meta-analizde antiviral tedavi olarak IFN- $\alpha$ 'nın proteinüri ve serum kreatinin düzeyi üzerinde etkin olduğunu ortaya koymuşlardır (74). IFN- $\alpha$ ile immünosupresif tedavinin etkinlik ve güvenliklerinin karşılaştırıldığı bir meta-analizde 6 aylık tedavi sonrası proteinüride anlamlı bir redüksiyon elde edildiği gösterilmiş ve MK varllğı tedaviye yanıt vermede pozitif prediktif bir ölçüt olarak tespit edilmiştir (75). Vigani ve ark. (76) HCV infeksiyonun nekroinflamatuar aktivitesini göstermeleri ve MK pozitif olan olgularda peg-IFN- $\alpha$ + RBV ile tedavi edilen tip 1-4 genotip HCV'de yüksek kalıcı virolojik yanıt ile ilişkili olduğunu bildirmişlerdir. El Khayat ve ark. (77) HCV genotip 4 hastalarında peg-IFN$\alpha+\mathrm{RBV}$ tedavisi ile MK pozitif olanlara göre yalnızca $\mathrm{HCV}$ pozitif olanlarda komplet remisyon oranları anlamlı yüksek bulmuşlardır.

Transplant böbrekte gelişen MPGN tedavi prensipleri de novo glomerülenefritlerle benzer olmakla birlikte, özellikle transplante böbrekte gelişen glomerülonefritlerde RBV monoterapisinin olası sakıncaları nedeniyle ihtiyatlı kullanılabilir (67-70). IFN tedavi rejimine kalıcı virolojik ve biyokimyasal cevabın oranının yüksek olmasına rağmen HCV ilişkili MPGN olgularında IFN tedavisi sonrasında nüks karaciğer hastalığı veya transplantasyonu sonrası rejeksiyon riski önemli bir sorun olabileceği iddia edilmiştir $(78,79)$. HCV pozitif renal allograft 15 'i transplantasyondan önce 1 yıl süreyle IFN- $\alpha$ alan 78 hastayı kapsayan bir çalışmada; IFN ile tedavi edilen 15 hastanın 10 (\%67)'unda transplantasyon sırasında HCV negatif hale gelişmişken, transplantasyon sırasinda HCV pozitif olan sadece 1 olguda posttransplant dönemde de novo glomerülonefrit rapor edilmiştir. Buna karşıllık, interferon almayan 63 allograft alıcısının \%29'unda nakil sırasında HCV RNA negatif iken, tamamı nakil öncesi HCV RNA pozitif olan 12 (\%19) olguda de novo glomerülonefrit geliştiği rapor edilmiştir (80). Bir çalışmada, peg-IFN- $\alpha$ monoterapisi alan böbrek transplant adaylarında kalıcı viral yanıt oranı yüzde 45 bulunmuş ve transplantasyon sonrası bu olguların 4'ünde HCV nüksü görülmemiştir $(81,82)$.

Hepatit C ile ilişkili MPGN tedavi süresi ile ilgili veriler açık değildir. Genel kanı; kısa dönem antiviral tedavi re- jimlerinin viral klirensi sağlamada yeterli olmayabileceğidir. Buna karşın çok uzun dönem tedavi protokollerinde tedavinin maliyet-etkinlik açısından avantajlı olmadıkları belirtilmektedir (79). Genel olarak antiviral tedavinin 1 yıl süre uygulanması önerilmektedir (56). Viral yanıtın iyi olmadığı durumlarda peg-IFN- $\alpha+$ RBV tedavisi 72 haftaya kadar uzatılabilir (64). Kalıcı virolojik yanıt için tedavi süresi sınırlandırılmamalıdır, zira tedavi süresinin uzaması ile renal manifestasyonlarda düzelme elde edilebileceği bildirilmektedir $(56,70)$.

3. Patogenetik Tedavi: HCV infeksiyonunun etkilediği glomerülde ciddi immün yanıtlar gözlendiği için şiddetli böbrek tutulumu (nefrotik sendrom, nefritik sendrom, ilerleyici böbrek yetmezliği, ya da ışık mikroskobu ile aktivite skoru yüksek glomerülonefrit varlığı) halinde, ilk tedavi olarak immünsupresif tedavi (kortikosteroid ve siklofosfamid) kullanılabilir (83). Ancak bu ilaçları kullanırken viral replikasyonu arttırma riski nedeniyle tedbirli olmak gerekmektedir (84).

Kortikosteroidler; nefrotik düzeyde proteinüri, hızlı ilerleyen böbrek fonksiyon bozuklukları gibi şiddetli böbrek tutulumu veya kriyoglobulinemide alevlenme gibi ciddi olgularda yüksek doz pulse glukokortikoid (oral prednizon $0,5-1,5 \mathrm{mg} / \mathrm{kg} / \mathrm{gün}$ veya intravenöz pulse metilprednizolon 0,5-1 g/gün) verilir. Akut faz kontrol altına alınana kadar doz azaltılarak $(0,5-1 \mathrm{mg} / \mathrm{kg} / \mathrm{gün})$ devam edilebilir. Kortikosteroidler; özellikle rituximab ile kombinasyonlarda önerilirken, kronik ve düşük doz kortikosteroid kullanımı viremiyi artırma riski ve hepatik lezyonu indükleyebileceği kuşkusuyla önerilmemektedir (56). IFN- $\alpha$ ve kortikosteroid kombinasyonu şiddetli renal disfonksiyon ve/veya ciddi MPGN ataklarında, IFN monoterapisine refrakter MPGN

Tablo 5. The Kidney Disease: Improving Global Outcomes (KDIGO) KBH'nda hepatit C için önerileri
eGFR $>50 \mathrm{~mL} / \mathrm{dk} / 1.73 \mathrm{~m}^{2}$, peg - IFN - a + RBV
- $\quad$ eGFR $15-50 \mathrm{~mL} / \mathrm{dk} / 1.73 \mathrm{~m}^{2}$, peg - IFN-a monoterapisi
- $\mathrm{eGFR}<15 \mathrm{~mL} / \mathrm{dk} / 1.73 \mathrm{~m}^{2}$ (hemodiyaliz hastaları dahil), standart IFN - a tedavisi (doz ayarlanması gerekir)
- Nefrotik düzeyde proteinüri ve/veya akut böbrek fonksiyon kaybı olan MPGN hastaları ve akut krioglobineminin alevlen- melerinde aşağıdaki tedavilerden biri düşünülmelidir;
o Plazmaferez; 2-3 hafta süre ile 3 seans/hafta 3 tt plazma değişimi
o Rituksimab; 4 hafta süre ile $375 \mathrm{mg} / \mathrm{m}^{2} /$ hafta
o Siklofosfamid; (2-4 ay süre ile $2 \mathrm{mg} / \mathrm{kg} / \mathrm{gün}$ ) + Metilpred- nizolon (3 gün süre ile 0,5-1 g/gün)
- Sistemik kriyoglobulinemi ve MPGN rölapslarında rituksimab ile tedavi edilebilir.
HCV ile ilişkili glomeruler hastalığı olanlarda proteinüriyi azalt- mak için anjiotensin (ADEI) veya anjiotensin reseptör blokörleri (ARB) kullanılmalıdır. 
ve potansiyel kısa dönem faydalı etkileri beklenen hastalarda kısa süreli yarar sağlayabilir, ancak uzun dönem sonuçları yüz güldürücü değildir (61).

Immünosupresif ilaçlar (Siklosporin, klorambusil ve azatioprin) B lenfosit proliferasyonunu, kriyoglobulin ve antikor üretimini baskılamak için kullanılabilir. En etkin ve en yaygın kullanılanı siklofosfamid olup ciddi MK pozitif olgularda kortikosteroidlerle birlikte remisyon elde etmek için kullanılır (82). Mikofenolat Mofetil (MMF), lenfosit proliferasyonunu daha selektif bloke etmesi, daha az toksik olması nedeniyle siklofosfamid'e alternatif olarak kullanılmasını öneren yazarlar vardır. Ayrıca MMF'in böbrek veya kalp nakli yapılmış HCV ile infekte bireylerde RBV ile inhibe edilebilen inosin monofosfat dehidrogenaz enzimini suprese edip viremiyi azalttığı iddia edilmiştir (85-87).

Fabrizi ve ark. (75) iki tedavi seçeneğinin (antiviral tedavi ve immünosupressif tedavi) karşılaştırıldığı 145 hastayı kapsayan 6 klinik çalışmanın meta-analizinde kortikosteroid tedavisine göre IFN tedavisinin proteinüriyi azaltmada daha etkin bulmuş (OR 3,86; \%95, CI 1,44-10,33; p=0,007), buna karşın serum kreatinin düzeylerinin düzelmesinde iki tedavi modalitesinin farksız olduğu ortaya koymuşlardır. Ayrıca antiviral tedavinin tamamlanmasından sonra proteinüri nüksü ile ilgili yeterli bilginin bulunmadığı not edilmiştir.

Plazmaferez; şiddetli, yaşamı tehdit eden hiperviskozite sendromu varlığında yaşam kurtarıcı olabilir ve ciddi olgularda remisyon elde etmek için diğer immünosupressiflerle birlikte kullanılmışır (88). Plazmaferez; sitokinler, immün kompleksler ve patojenik unsurları uzaklaştırarak, antijen antikor oranlarında değiştirir ve endotelin yenilenmesini stimüle ederek etki gösterir $(89,90)$. Kriyoglobulin üretimi üzerinde etkili olmadığı için uzun dönem kullanımda efektif değildir. $\mathrm{Bu}$ nedenle plazmaferez ile birlikte kullanılan immünsupresif ilaçlar rebound immün reaksiyonları önlemek için 4-6 hafta daha devam edilmelidir (91). Plazmaferez hem geleneksel plazma değişimi hem de daha yeni ve ilgi çekici bir yöntem olan çifte filtrasyonlu plazma değişimi (Double-Filtration Plasmapheresis, DFPP) ile dolaşan immün kompleksler ve kriyoglobulinleri uzaklaştırmada etkilidir. Geleneksel plazmaferezden farklı olarak DFPP küçük çaplı porlarla plazma komponentlerini ayırır, büyük moleküler ağırlıklı proteinler atılır ve albümin gibi küçük moleküler ağırlıklı substanslar hastaya geri verilir. Ayrıca DFPP'de reinfüzyon solüsyonu gerekmemektedir. Fujiwara ve ark. (92) HCV genotip 1b olgularında DFPP+IFN- $\alpha$ tedavisi ile viral yükte anlamlı düşüş elde etmelerinden sonra benzer sonuçlar rapor eden çalışmalar da literatürde yayınlanmıştır (93). MK pozitif olgularda başarılı bir şekilde uygulandığına dair veriler olmasına karşın randomize kontrollü çalışma bulunmamaktadır. Plazmaferez siklofosfamide ile de kombine edilebilir (94).

Rituksimab (RTX); steroid ve immünosupresif tedaviye yanıtsız, ciddi vaskülit ve/veya periferik nöropati ile birlikte olan olgularda şimerik monoklonal antikor olan Rituksimab (anti-CD20) ile patogenetik tedavide özellikle otoimmün komponenti olan hastalarda umut verici sonuçlar alınabilir (95). Rituksimab; B hücrelerini tüketerek potansiyel plazma hücrelerinin azalmasına neden olur. Ayrica monoklonal IgM üretimini engelleyerek kriyoglobulin sentezi ve immünkomplekslerin böbreklerde depozisyonunu önler (95, 96). Bazı küçük çaplı çalışmalarda, rituksimab ile Peg-IFNa + RBV kombinasyonu, Peg-IFN- $\alpha+$ RTX'den daha etkin bulunmuştur $(97,98)$. Roccatello ve ark. (99) MK ilişkili HCV olgularında RTX tedavisi ile serum kreatinin ve protein düzeylerinde anlamlı düşüşs sağlamışlardır. Saadoun ve ark. (100) HCV ile ilişkili sendrom nedeniyle RTX kullanılmış olan 13 çalışmayı analiz etmişler ve en iyi sonucun glomerülonefritli (\%70) olgularda olduğunu rapor etmişlerdir.

Rituksimaba ortalama yanıt 1 yıldır ve rölaps sıktır. Relapslarda rituksimab'in tekrar kullanılıp kullanılmayacağı konusunda yeterli bilgi yoktur (101). Yanıtsız olgularda oral siklofosfamid ve plazmaferez denenebilir. Plazmaferez RBV ile birlikte adjuvan tedavi olarak sınırlı vakada denenmiş ve etkin bulunmuştur (61). HCV pozitif veya negatif renal transplant alıcılarında gelişen kriyoglobulinemik MPGN'de RTX ile etkin bir şekilde tedavi edilmiş olmasına rağmen infeksiyöz komplikasyonların sıklığı dikkati çekmiştir (102). RTX monoterapisi alan tip $2 \mathrm{MK}(+) \mathrm{HCV}$ ilişkili aktif glomerülonefritli 5 hastada RTX etkin bulunmuş, steroid gibi immünsupresif tedavilerin RTX'a eklenmesinin zararlı olabileceğini düşündürmüştür (103). De Vita ve ark. (104) yaptıkları prospektif, randomize-kontrollü çalışmada şiddetli kriyoglobulinemik 59 hastada RTX monoterapisinin kortikosteroidler, siklofosfamid ve plazmaferez gibi geleneksel tedavilerden üstün olduğunu ortaya koymuşlardır.

Hepatit C ile ilişkili MPGN patogenezi anlaşılmaya devam edildikçe yeni terapötik girişimleri denenmiştir. Tümör nekrozis faktör (TNF)- $\alpha$ veya interleukin (IL)-1 reseptör antagonistleri gibi selektif anti-inflamatuar ilaçlar kullanımı ile ilgili veriler çok yenidir. Ayrıca eculizumab (anti-C5 antikoru) gibi tedavi stratejileri deneme aşamasındadır (105).

KDIGO önerileri; The Kidney Disease: Improving Global Outcomes (KDIGO) 2008'de KBH'nda hepatit C için rehber yayınlanmıştır (106). Buna göre HCV ile ilişkili glomerüler hastalıklarda tahmini glomerüler filtrasyon hızına (eGFR) göre antiviral tedavi önerilmektedir. KDIGO rehberi önerileri Tablo 5 'te özetlenmiştir. Monoterapiden sonra gelişen rölapsta Peg-IFN- $\alpha+$ RBV verilmesi önerilmektedir (eGFR $>50 \mathrm{~mL} / \mathrm{dk}$ olmalı).

Prognoz: HCV ile ilişkili GN remisyon ve relaps peryodları gösterebilir. MPGN uzun dönem kronik böbrek hastalığına progresyon gösterir ve bu durum kişiden kişiye değişkenlik gösterir. Genel olarak MK ile ilişkili vaskülit gelişen ve vaskülitin ekstrarenal manifestasyonu olan olgularda renal prognoz iyi değildir $(4,7,14)$. Hastaların \%50'si 10 yıl için- 
de SDBY'e progresyon gösterir. Ortalama yaşam tanıdan sonra \%50-60 olguda 10 yıldır.

\section{Sonuç}

HCV pozitif popülasyonda glomerüler lezyonlar sik olmamakla birlikte potansiyel olarak ciddi ve yaşamı tehdit eden böbrek patolojileri meydana gelebilir. HCV ilişkili en yaygın glomerülopati MPGN'dir. Daha az sıklıkla nonkriyoglobulinemik MPGN, membranöz glomerülonefrit ve mezangioproliferatif glomerülonefrit görülebilir. MPGN, kriyoglobulinemik olgularda görülür ve immün kompleks mekanizma ile oluştuğu düşünülmektedir. Tanı çeşitli laboratuar testleri ile konulabilir. Kesin tanı için böbrek biyopsisi gereklidir. Tedavide böbrek tutulumunun ciddiyeti belirleyicidir. Tüm hastalara anjiotensin-dönüştürücü enzim inhibitörleri veya anjiotensin reseptör antagonisti ilaçlar, antilipidemik ilaçların yanı sıra anti-HCV tedavi verilmelidir. Hafif olgularda konservatif tedavi yeterli iken orta ve ağır olgularda antiviral tedavi (Peg-IFN- $\alpha+R B V)$, immünosupresyon, plazmaferez ve seçilmiş olgularda rituksimab vb. gibi tedaviler uygulanabilir. Uzun dönem renal prognoz iyi değildir.

Conflict of Interest: No conflict of interest was declared by the authors.

Financial Disclosure: The authors declared that this study has received no financial support.

Peer-review: Externally peer-reviewed.

Author Contributions: Concept - D.Ş.; Design - D.Ş.; Supervision - D.Ş., B.E., M.E.Y.; Funding - D.Ş.; Materials - D.Ş. B.E., M.E.Y.; Data Collection and/or Processing - D.Ş.; Analysis and/or Interpretation - D.Ş., M.E.Y.; Literature Review - D.Ş., B.E., M.E.Y.; Writing - D.Ş.; Critical Review - D.Ş., B.E.

Acknowledgement: The Authors thank to Dr. Ahmet Engin Atay for his contributions to the abstract and grammar editing of the review.

Çıkar Çatışması: Yazarlar çıkar çatışması bildirmemişlerdir.

Finansal Destek: Yazarlar bu çalışma için finansal destek almadıklarını beyan etmişlerdir.

\section{Hakem değerlendirmesi: Dış bağımsız.}

Yazar Katkıları: Fikir - D.Ş; Tasarım - D.Ş; Denetleme - D.Ş., B.E., M.E.Y.; Kaynaklar - D.Ş.; Malzemeler - D.Ş., B.E., M.E.Y.; Veri toplanması ve/veya işlemesi - D.Ş.; Analiz ve/veya yorum - D.Ş., M.E.Y.; Literatür taraması - D.Ş., B.E., M.E.Y.; Yazıyı yazan - D.Ş .; Eleştirel İnceleme - D.Ş., B.E.

Teşekkür: Yazarlar, derlemenin İngilizce özet ve gramer redaksiyonuna katkılarından dolayı Dr. Ahmet Engin Atay’a teșekkür eder.

\section{Kaynaklar}

1. Houghton $\mathrm{M}$. The long and winding road leading to the identification of the hepatitis C virus. J Hepatol 2005; 51: 939-48. [CrossRef]
2. World Health Organization. Hepatitis C. www.who.int/csr/disease/hepatitis/whocdscsrlyo2003/en/index1.html

3. Alter MJ. Epidemiology of hepatitis C virus infection. World J Gastroenterol 2007; 13: 2436-41.

4. Khattab MA, Eslam M, Alavian SM. Hepatitis C Virus as a Multifaceted Disease: A Simple and Updated Approach for Extrahepatic Manifestations of Hepatitis C Virus Infection. Hepat Mon 2010; 10: 258-69.

5. Alpers CE, Smith KD. Cryoglobulinemia and renal disease. Curr Opin Nephrol Hypertens 2008; 17: 243-9. [CrossRef]

6. Sabry AA, Sobh MA, Irving WL, Grabowska A, Wagner BE, Fox $S$, et al. A comprehensive study of the association between hepatitis C virus and glomerulopathy. Nephrol Dial Transplant 2002; 17: 239-45. [CrossRef]

7. Latt N, Alachkar N, Gurakar A. Hepatitis C virus and its renal manifestations: a review and update. Gastroenterol Hepatol (N Y) 2012; 8: 434-45.

8. Demirtürk N, Demirdal T, Toprak D, Altindiş M, Aktepe OC. Hepatitis B and C virus in West-Central Turkey: Seroprevalence in healthy individuals admitted to a university hospital for routine health checks. Turk J Gastroenterol 2006; 17: 267-72.

9. Pascual M, Perrin L, Giostra E, Schifferli JA. Hepatitis C virus in patients with cryoglobulinemia type II [letter]. J Infect Dis 1990; 162: 569-70. [CrossRef]

10. Ali A, Zein NN. Hepatitis C infection: A systemic disease with extrahepatic manifestations. Cleve Clin J Med 2005; 72: 1005-8. [CrossRef]

11. Johnson RJ, Gretch DR, Yamabe H, Hart J, Bacchi CE. Membranoproliferative glomerulonephritis associated with hepatitis $\mathrm{C}$ virus infection. N Engl J Med 1993; 328: 465-70. [CrossRef]

12. Kasuno K, Ono T, Matsumori A, Nogaki F, Kusano H. Hepatitis C virus-associated tubulointerstitial injury. Am J Kidney Dis 2003; 41: 767-75. [CrossRef]

13. Süleymanlar G, Altıparmak MR, Seyahi N, Trabulus S. T.C. Sağlık Bakanlığı ve Türk Nefroloji Derneği ortak raporu. Registry 2012. Türk Nefroloji Derneği Yayınları; Miki Matbaacılık San. ve Tic. Ltd. Şti. Ankara 2013.

14. Tsui JI, Vittinghoff E, Shlipak MG, Bertenthal D, Inadomi J, Rodriguez RA, et al. Association of hepatitis $\mathrm{C}$ seropositivity with increased risk for developing end-stage renal disease. Arch Intern Med 2007; 167: 1271-6. [CrossRef]

15. Perico N, Cattaneo D, Bikbov B, Remuzzi G. Hepatitis C Infection and Chronic Renal Diseases. Clin J Am Soc Nephrol 2009; 4: $207-$ 20. [CrossRef]

16. Butt AA, Wang X, Fried LF. HCV Infection and the Incidence of CKD. Am J Kidney Dis 2011; 57: 396-402. [CrossRef]

17. Liangpunsakul S, Chalasani N. Relationship between hepatitis $C$ and microalbuminuria: results from the NHANES III. Kidney Int 2005; 67: 285-90. [CrossRef]

18. Misiani R, Bellavita P, Fenili D, Borelli G, Marchesi D, Massazza $\mathrm{M}$, et al. Hepatitis $\mathrm{C}$ virus infection in patients with essential mixed cryoglobulinemia. Ann Intern Med 1992; 117: 573-7. [CrossRef]

19. Roccatello D, Fornasieri A, Giachino O, Rossi D, Beltrame A, Banfi G, et al. Multicenter study on hepatitis $\mathrm{C}$ virus-related cryoglobulinemic glomerulonephritis. Am J Kidney Dis 2007; 49: 69-82. [CrossRef]

20. Ferri C. Mixed cryoglobulinemia. Orphanet J Rare Dis 2008; 3: 25. [CrossRef]

21. Sansonno D, Dammacco F. Hepatitis C virus, cryoglobulinaemia, and vasculitis: immune complex relations. Lancet Infect Dis 2005; 5: 227-36. [CrossRef]

22. Ramos-Casals M, Trejo O, García-Carrasco M, Cervera R, Font J. Mixed cryoglobulinemia: New concepts. Lupus 2000; 9: 83-91. [CrossRef] 
23. Tedeschi A, Baratè C, Minola E, Morra E. Cryoglobulinemia. Blood Rev 2007; 21: 183-200. [CrossRef]

24. Brouet JC, Clauvel JP, Danon F, Klein M, Seligmann M. Biologic and clinical significance of cryoglobulins. A report of 86 cases. Am J Med 1974; 57: 775-88. [CrossRef]

25. Meltzer M, Franklin EC, Elias K, McCluskey RT, Cooper N. Cryoglobulinemia: A clinical and laboratory study. Am J Med 1996; 40: 837-56. [CrossRef]

26. Monti G, Galli M, Invernizzi F, Pioltelli P, Saccardo F, Monteverde A, et al. Cryoglobulinemias: A multicentre study of the early clinical and laboratory manifestations of primary and secondary disease. Italian Group for the Study of Cryoglobulinaemias (GISC). QJM 1995; 88: 115-26.

27. Sansonno D, Carbone A, De Re V, Dammacco F. Hepatitis C virus infection, cryoglobulinemia, and beyond. Rheumatology 2007; 46: 572-8. [CrossRef]

28. Charles ED, Dustin LB. Hepatitis C virus-induced cryoglobulinemia. Kidney Int 2009; 76: 818-24. [CrossRef]

29. Matignon M, Cacoub P, Colombat M, Saadoun D, Brocheriou I, Mougenot B, et al. Clinical and morphologic spectrum of renal involvement in patients with mixed cryoglobulinemia without evidence of hepatitis C virus infection. Medicine (Baltimore) 2009; 88: 341-8. [CrossRef]

30. Trejo O, Ramos-Casals M, García-Carrasco M, Yagüe J, Jiménez S, de la Red G, et al. Cryoglobulinemia: study of etiologic factors and clinical and immunologic features in 443 patients from a single center. Medicine (Baltimore) 2001; 80: 252-62. [CrossRef]

31. Fabrizi F, Plaisier E, Saadoun D, Martin P, Messa P, Cacoub P. Hepatitis $C$ virus infection, mixed cryoglobulinemia, and kidney disease. Am J Kidney Dis 2013; 61: 623-37. [CrossRef]

32. Agnello V. The etiology and pathophysiology of mixed cryoglobulinemia secondary to hepatitis $C$ virus infection. Springer Semin Immunopathol 1997; 19: 111-29. [CrossRef]

33. Mazzaro C, Panarello G, Tesio F, Santini G, Crovatto M, Mazzi G, et al. Hepatitis $\mathrm{C}$ virus risk: a hepatitis $\mathrm{C}$ virus related syndrome. J Intern Med 2000; 247: 535-45. [CrossRef]

34. Franguel L, Musset L, Cresta P, Cacoub P, Huraux JM, Lunel F. Hepatitis $C$ virus genotypes and subtypes in patients with hepatitis $\mathrm{C}$ with and without cryoglobulinemia. J Hepatol 1996; 25: 42732. [CrossRef]

35. Petrarca A, Rigacci L, Caini P, Colagrande S, Romagnoli P, Vizzutti $\mathrm{F}$, et al. Safety and efficacy of rituximab in patients with hepatitis $\mathrm{C}$ virus-related mixed cryoglobulinemia and severe liver disease. Blood 2010; 116: 335-42. [CrossRef]

36. Cacoub P, Renou C, Kerr G, Hüe S, Rosenthal E, Cohen P, et al. Influence of HLA-DR phenotype on the risk of hepatitis $\mathrm{C}$ virusassociated mixed cryoglobulinemia. Arthritis Rheum 2001; 44: 2118-24. [CrossRef]

37. Congia M, Clemente MG, Dessi C, Cucca F, Mazzoleni AP, Frau F, et al. HLA class II genes in chronic hepatitis $\mathrm{C}$ virus-infection and associated immunological disorders. Hepatology 1996; 24: 133841. [CrossRef]

38. Ferri C, Sebastiani M, Giuggioli D, Cazzato M, Longombardo G, Antonelli A, et al. Mixed cryoglobulinemia: demographic, clinical, and serologic features and survival in 231 patients. Semin Arthritis Rheum 2004; 33: 355-74. [CrossRef]

39. Sumida K, Ubara Y, Hoshino J, Suwabe T, Nakanishi S, Hiramatsu $\mathrm{R}$, et al. Hepatitis $\mathrm{C}$ virus-related kidney disease: various histological patterns. Clin Nephrol 2010; 74: 446-56.

40. Morales J. Hepatitis $C$ virus infection and renal disease after renal transplantation. Transplant Proc 2004; 36: 760-2. [CrossRef]

41. Meyers CM, Seeff LB, Stehman-Breen CO, Hoofnagle JH. Hepatitis $C$ and renal disease: An update. Am J Kidney Dis 2003; 42: 631-57. [CrossRef]
42. Kitamura T, Nakase H, Iizuka H. Henoch-Schonlein purpura after postoperative Staphylococcus aureus infection with hepatic IgA nephropathy. J Nephrol 2006; 19: 687-90.

43. Kamar N, Izopet J, Alric L, Guilbeaud-Frugier C, Rostaing L. Hepatitis $\mathrm{C}$ virus-related kidney disease: an overview. Clin Nephrol 2008; 69: 149-60. [CrossRef]

44. Dizer U, Beker CM, Yavuz I, Ortatatli M, Ozguven V, Pahsa A. Minimal change disease in a patient receiving IFN-alpha therapy for chronic hepatitis $\mathrm{C}$ virus infection. J Interferon Cytokine Res 2003; 23: 51-4. [CrossRef]

45. Markowitz GS, Cheng JT, Colvin RB, Trebbin WM, D’Agati VD. Hepatitis $\mathrm{C}$ viral infection is associated with fibrillary glomerulonephritis and immunotactoid glomerulopathy. J Am Soc Nephrol 1998; 9: 2244-52.

46. Cruzado JM, Carrera M, Torras J, Grinyo JM. Hepatitis C virus infection and de novo glomerular lesions in renal allografts. Am J Transplant 2001; 1: 171-8. [CrossRef]

47. Maluf DG, Archer KJ, Mas VR. Kidney grafts from HCV-positive donors: advantages and disadvantages. Transplant Proc 2010; 42: 2436-46. [CrossRef]

48. Romero E, Galindo P, Bravo JA, Osorio JM, Pérez A, Baca Y, et al. Hepatitis $C$ virus infection after renal transplantation. Transplant Proc 2008; 40: 2933-5. [CrossRef]

49. Ozdemir BH, Ozdemir FN, Sezer S, Colak T, Haberal M. De novo glomerulonephritis in renal allografts with hepatitis $\mathrm{C}$ virus infection. Transplant Proc 2006; 38: 492-5. [CrossRef]

50. Llotta K. Beyond Heparenal Syndrome: Glomerulonephritis in patients with Liver disease. Sem Nephrol 2002; 22: 302-8.

51. Hayat A, Mitwalli A. Hepatitis C and kidney disease. Hepat Res Treat 2010; 2010: 534327.

52. Ferri C, Puccini R, Longombardo G, Paleologo G, Migliorini P, Moriconi L, et al. Low-antigen-content diet in the treatment of patients with IgA nephropathy. Nephrol Dial Transplant 1993; 8: 1193-8.

53. Rozin AP, Lewin M, Braun-Moscovici $Y$, Itzhak OB, Bergman R, Balbir-Gurman A, et al. Essential mixed cryoglobulinemia type II. Clin Exp Rheumatol. 2006; 24: 329-32.

54. Chadban SJ, Atkins RC. Glomerulonephritis. Lancet 2005; 365: 1797-806. [CrossRef]

55. Fabrizi F, Fogazzi GB, Cresseri D, Passerini P, Martin P, Donato MF, et al. Antiviral Therapy for HCV-Associated Cryoglobulinemic Glomerulonephritis: Case Report and Review of the Literature. Kidney Blood Press Res 2012; 35: 687-93. [CrossRef]

56. Fabrizi F, Lunghi G, Messa M, Martin P. Therapy of hepatitis C virus-associated glomerulonephritis: current approaches. J Nephrol 2008; 21: 813-25.

57. Ruggenenti P, Schieppati A, Remuzzi G. Progression, remission, regression of chronic renal diseases. Lancet 2001; 357: 1601-8. [CrossRef]

58. Rossi P, Bertani T, Baio P, Caldara R, Luliri P, Tengattini F, et al. Hepatitis C virus-related cryoglobulinemic glomerulonephritis: long-term remission after antiviral therapy. Kidney Int 2003; 63: 2236-41. [CrossRef]

59. Garini G, Allegri L, Lannuzzella F, Vaglio A, Buzio C. HCV-related cryoglobulinemic glomerulonephritis: implications of antiviral and immunosuppressive therapies. Acta Biomed 2007; 78: 51-9.

60. Dávalos Moscol M. Indications for treatment in chronic HCV infection. Ann Hepatol 2010; 9: 49-53.

61. Kamar N, Rostaing L, Alric L. Treatment of hepatitis C-virus-related glomerulonephritis. Kidney Int 2006; 69: 436-9. [CrossRef]

62. Fujiwara K, Yokosuka O, Komine F, Moriyama M, Kato N, Yoshida H, et al. Tokyo Hepatitis Network. Twenty-four weeks of interferon alpha- $2 \mathrm{~b}$ in combination with ribavirin for Japanese hepatitis 
C patients: sufficient treatment period for patients with genotype 2 but not for patients with genotype 1. Liver Int 2006; 26: 520-8. [CrossRef]

63. Flisiak R, Parfieniuk A. Investigational drugs for hepatitis C. Expert Opin Investig Drugs 2010; 19: 63-75. [CrossRef]

64. McHutchison JG, Lawitz EJ, Shiffman ML, Muir AJ, Galler GW, McCone J, et al; IDEAL Study Team. Peginterferon alfa-2b or alfa2a with ribavirin for treatment of hepatitis $\mathrm{C}$ infection. $\mathrm{N}$ Engl J Med 2009; 361: 580-93. [CrossRef]

65. Sugiura T, Yamada T, Kimpara Y, Fujita N, Goto K, Koyama N, et al. Effects of pegylated interferon alpha-2a on hepatitis-C-virusassociated glomerulonephritis. Pediatr Nephrol 2009; 24: 199-202. [CrossRef]

66. Nelson DR, Benhamou Y, Chuang WL, Lawitz EJ, Rodriguez-Torres M, Flisiak R, et al; ACHIEVE-2/3 Study Team. Albinterferon Alfa- $2 b$ was not inferior to pegylated interferon- $\alpha$ in a randomized trial of patients with chronic hepatitis $\mathrm{C}$ virus genotype 2 or 3 . Gastroenterology 2010; 139: 1267-76. [CrossRef]

67. Bruchfeld A, Lindahl K, Ståhle L, Soderberg M, Schvarcz R et a.l. Interferon and ribavirin treatment in patients with hepatitis C-associated renal disease and renal insufficiency. Nephrol Dial Transplant 2003; 18: 1573. [CrossRef]

68. Johnson RJ, Gretch DR, Couser WG, Alpers CE, Wilson J, Chung $\mathrm{M}$, et al. Hepatitis $\mathrm{C}$ virus-associated glomerulonephritis. Effect of alpha-interferon therapy. Kidney Int 1994; 46: 1700. [CrossRef]

69. Landau DA, Saadoun D, Halfon P, Martinot-Peignoux M, Marcellin P, Fois E, Cacoub P, et al. Relapse of hepatitis C virus-associated mixed cryoglobulinemia vasculitis in patients with sustained viral response. Arthritis Rheum 2008; 58: 604-11. [CrossRef]

70. Cacoub P, Saadoun D, Limal N, Sene D, Lidove O, Piette JC. PEGylated interferon alfa- $2 \mathrm{~b}$ and ribavirin treatment in patients with hepatitis $\mathrm{C}$ virus-related systemic vasculitis. Arthritis Rheum 2005; 52: 911-5. [CrossRef]

71. Mazzaro C, Zorat F, Caizzi M, Donada C, Di Gennaro G, et Maso $\mathrm{LD}$, et al. Treatment with peg-interferon alfa- $2 \mathrm{~b}$ and ribavirin of hepatitis $C$ virus-associated mixed cryoglobulinemia: A pilot study. J Hepatol 2005; 42: 632-8. [CrossRef]

72. Campise M, Tarantino A. Glomerulonephritis in mixed cryoglobulinaemia: What treatment? Nephrol Dial Transplant 1999; 14: 281-3. [CrossRef]

73. Yu ML, Chuang WL, Dai CY, Lee LP, Hsieh MY, Lin ZY, et al. Different viral kinetics between hepatitis $\mathrm{C}$ virus genotype 1 and 2 as on-treatment predictors of response to a 24-week course of highdose interferon-alpha plus ribavirin combination therapy. Translational Res 2006; 148: 120-7. [CrossRef]

74. Feng B, Eknoyan G, Guo ZS, Jadoul M, Rao HY, Zhang W, et al. Wei L. Effect of interferon-alpha-based antiviral therapy on hepatitis $\mathrm{C}$ virus-associated glomerulonephritis: a meta-analysis. Nephrol Dial Transplant 2012; 27: 640-6. [CrossRef]

75. Fabrizi F, Bruchfeld A, Mangano S, Dixit V, Messa P, Martin P. Interferon therapy for HCV-associated glomerulonephritis: metaanalysis of controlled trials. Int J Artif Organs 2007; 30: 212-9.

76. Vigani AG, Macedo de Oliveira A, Tozzo R, Pavan MH, Gonçales ES, et al. The association of cryoglobu-linaemia with sustained virological response in patients with chronic hepatitis C. J Viral Hepat 2011; 18: 91-8. [CrossRef]

77. El Khayat HR, Fouad YM, Ahmad EA, El-Amin H, Ismael F, Rizk A.et al. Hepatitis $\mathrm{C}$ virus (genotype 4)-associated mixed cryoglobulinemia vasculitis: effects of antiviral treatment. Hepatol Int 2012; 6: 606-12. [CrossRef]

78. Casanovas-Taltavull T, Baliellas C, Benasco C, Serrano TT, Casanova $\mathrm{A}$, et al. Efficacy of interferon for chronic hepatitis $\mathrm{C}$ virusrelated hepatitis in kidney transplant candidates on hemodialysis: results after transplantation. Am J Gastroenterol 2001; 96: 1170. [CrossRef]

79. Espinosa M, Rodriguez M, Martin-Malo A, Alvarez de Lara MA, Gonzalez R Lopez-Rubio F, et al. Interferon therapy in hemodialysis patients with chronic hepatitis $\mathrm{C}$ virus infection induces a high rate of long-term sustained virological and biochemical response. Clin Nephrol 2001; 55: 220.

80. Cruzado JM, Casanovas-Taltavull T, Torras J, Baliellas C, GilVernet S, Grinyó JM, et al. Pretransplant interferon prevents hepatitis $\mathrm{C}$ virus-associated glomerulonephritis in renal allografts by HCV-RNA clearance. Am J Transplant 2003; 3: 357. [CrossRef]

81. Werner T, Aqel B, Balan V, Byrne T, Carey E, Douglas D, et al. Treatment of hepatitis $\mathrm{C}$ in renal transplantation candidates: a single-center experience. Transplantation 2010; 90: 407. [CrossRef]

82. Abbott KC, Bucci JR, Matsumoto CS, Swanson SJ, Agodoa LY, Holtzmuller KC, et al. Cruess DF, Peters TG. Hepatitis C and renal transplantation in the era of modern immunosuppression. J Am Soc Nephrol 2003; 14: 2908-18. [CrossRef]

83. Fabrizi F, Colucci P, Ponticelli C, Locatelli F. Kidney and liver involvement in cryoglobulinemia. Semin Nephrol 2002; 22: 309-18.

84. Lake JR. The role of immunosuppression in recurrence of hepatitis C. Liver Transpl 2003; 9: 63-6. [CrossRef]

85. Ramos-Casals M, Muñoz S, Medina F, Jara LJ, Rosas J, Calvo-Alen J, et al. HISPAMEC Study Group. Systemic autoimmune diseases in patients with hepatitis $\mathrm{C}$ virus infection: characterization of 1020 cases (The HISPAMEC Registry). J Rheumatol 2009; 36: 1442-8. [CrossRef]

86. Pietrogrande M, Devita S, Zignego A, Pioltelli P, Sansonno D, Sollima $S$, et al. Recommendations for the management of mixed Cryoglobulinemia syndrome in Hepatitis $\mathrm{C}$ virus-infected patients. Autoimmun Rev 2011; 10: 444-54. [CrossRef]

87. Reed MJ, Alexander GJ, Thiru S, Smith KG. Hepatitis C-associated glomerulonephritis - a novel therapeutic approach. Nephrol Dial Transplant 2001; 16: 869-71. [CrossRef]

88. Bombardieri S, Ferri C, Paleologo G, Bibolotti E, Camici M, Fosella PV, et al. Prolonged plasma exchange in the treatment of renal involvement in essential mixed cryoglobulinemia. Int J Artif Organs 1983; 6: 47-50.

89. Guillevin L, Pagnoux C. Indications of plasma exchanges for systemic vasculitides. TherApher Dial 2003; 7: 155-60. [CrossRef]

90. Drew MJ. Plasmapheresis in the dysproteinemias. TherApher 2002; 6: 45-52. [CrossRef]

91. Scarpato S, Tirri E, Naclerio C, Moscato P, Salvati G. Plasmapheresis in cryoglobulinemic neuropathy: a clinical study. Dig Liver Dis 2007; 39: 136-7. [CrossRef]

92. Fujiwara K, Kaneko S, Kakumu S, Sata M, Hige S. Double filtration plasma-pheresis and interferon combination therapy for chronic hepatitis $\mathrm{C}$ patients with genotype 1 and high viral load. Hepatol Res 2007; 37: 701-10. [CrossRef]

93. Kim SR, Saito J, Imoto S, Komaki T, Nagata Y, Kim KI, et al. Double-filtration plasmapheresis plus interferon- $\beta$ for HCV- $1 \mathrm{~b}$ patients with non-sustained virological response to previous combination therapy. Digestion 2011; 84: 10-6. [CrossRef]

94. Alchi B, Jayne D. Membranoproliferative glomerulonephritis. Pediatr Nephrol 2010; 25: 1409-18. [CrossRef]

95. Ahmed MS, Wong CF. Should rituximab be the rescue therapy for refractory mixed cryoglobulinemia associated with hepatitis C? J Nephrol 2007; 20: 350-6.

96. Sansonno D, De Re V, Lauletta G, Tucci FA, Boiocchi M, Dammacco F. Monoclonal antibody treatment of mixed cryoglobulinemia resistant to interferon alpha with an anti-CD20. Blood. 2003; 101: 3818-26. [CrossRef]

97. Saadoun D, Resche Rigon M, Sene D, Terrier B, Karras A, et al. Rituximab plus Peg-Interferon \{alpha\} /ribavirin compared to Peg- 
Interferon \{alpha\}/ribavirin in Hepatitis C related mixed cryoglobulinemia. Blood 2010; 116: 326-34. [CrossRef]

98. Dammacco F, Tucci FA, Lauletta G, Gatti P, De Re V, Conteduca $\mathrm{V}$, et al. Pegylated interferon-\{alpha\}, ribavirin, and rituximab combined therapy of hepatitis $\mathrm{C}$ virus-related mixed cryoglobulinemia: a long-term study. Blood 2010; 116: 343-53. [CrossRef]

99. Roccatello D, Baldovino S, Rossi D, Mansouri M, Naretto C, Gennaro $\mathrm{M}$, et al. Long-term effects of anti-CD20 monoclonal antibody treatment of cryoglobulinaemic glomerulonephritis. Nephrol Dial Transplant 2004; 19: 30-54. [CrossRef]

100. Saadoun D, Delluc A, Piette JC, Cacoub P. Treatment of hepatitis C-associated mixed cryoglobulinemia vasculitis. Curr Opin Rheumatol 2008; 20: 23-8. [CrossRef]

101. Pescovitz MD. Rituximab, an anti-cd20 monoclonal antibody: History and mechanism of action. Am J Transplant 2006; 6: 859-66. [CrossRef]

102. Basse G, Ribes D, Kamar N, Mehrenberger M, Sallusto F. Rituximab therapy for mixed cryoglobulinemia in seven renal transplant patients. Transplant Proc 2006; 38: 2308-10. [CrossRef]
103. Quartuccio L, Soardo G, Romano G, Zaja F, Scott CA, De Marchi G, et al. Rituximab treatment for glomeru-lonephritis in HCVassociated mixed cryoglobulinaemia: efficacy and safety in the absence of steroids. Rheumatology (Oxford) 2006; 45: 842-6. [CrossRef]

104. De Vita S, Quartuccio L, Isola M, Mazzaro C, Scaini P, Lenzi M, et al. A randomized controlled trial of rituximab for the treatment of severe cryoglobulinemic vasculitis. Arthritis Rheum 2012; 64: 843-53. [CrossRef]

105. Kamar N, Izopet J, Alric L, Guilbeaud-Frugier C, Rostaing L. Hepatitis $\mathrm{C}$ virus-related kidney disease: An overview. Clin Nephrol 2008; 69: 149-60. [CrossRef]

106. Kidney Disease Improving Global Outcomes. KDIGO clinical practice guidelines for the prevention, diagnosis, evaluation and treatment of hepatitis $\mathrm{C}$ in chronic kidney disease. Kidney Int 2008; 73: 1-99.

107. Ferri C, AL, Zignego AL, Pileri SA. Cryoglobulins. J Clin Pathol 2002; 55: 4-13. [CrossRef] 